\title{
A Finite Element Analysis on Stress Distribution in Overdenture Implants and Implant Abutment Interface Using Different Attachment Systems: An In Vitro Study
}

\author{
Aquib Javaid ${ }^{1} \quad$ Tarun Kalra $^{1} \quad$ Manjit Kumar $^{1} \quad$ Ajay Bansal ${ }^{1} \quad$ Udey Singh Wirring ${ }^{1}$ \\ 1Department of Prosthodontics, Bhojia Dental College and Hospital, \\ Address for correspondence Aquib Javaid, MDS, Department of \\ Baddi, Solan, Himachal Pradesh, India \\ Prosthodontics, Bhojia Dental College and Hospital, Baddi, Solan, \\ Himachal Pradesh, India (e-mail: aquib.mughal@gmail.com).
}

Dent J Adv Stud 2020;8:22-31

\begin{abstract}
Introduction The overdenture is an alternative to fixed implant-supported prosthesis for its relatively low-cost and in clinical cases where it is impossible to place multiple implants with appropriate number and arrangement in the arch to support a fixed prosthesis. In implant-supported overdentures, many attachments such as bars, ball, and magnets can be used. The anchorage system affects the retention and stability of the overdenture as well as the load transfer to the implant and the bone. The purpose of this study was to evaluate the exerted stresses on implants and implant-abutment interface by comparing different attachment systems used for implant-supported maxillary and mandibular overdentures using finite-element analysis.

Materials and Methods Stress distribution in five different models with different attachments were evaluated using finite-element analysis. The studied attachment systems were Ball/O-ring and bar-clip attachments. Three models in mandible were studied, two implants with ball attachments, two implants with bar, and four implants connected with a bar. In maxilla, two models were studied, four implants with ball attachments, and four implants connected with bar. Forces were applied bilaterally on each model in the canine and molar region separately. The forces applied were 35N

Keywords

- finite-element analysis

- attachments

- implant-supported overdenture axially, $70 \mathrm{~N}$ obliquely, and $10 \mathrm{~N}$ horizontally.

Results The ball attachments models showed the highest amount of stresses on the bone and on the implants in maxilla and mandible. The bar-clip attachment with four implants showed least stress in maxilla as well as in the mandible. The bar on four implants has better stress distribution as compared with the bar on the two implants.
\end{abstract}

\section{Introduction}

The vast advances in medical care have significantly increased the average life span of humans, rendering a large geriatric population edentulous. WHO has classified edentulous people as physically impaired as the reduced number of teeth makes mastication more difficult. ${ }^{1}$ Complete denture patients frequently report problems with oral function, mainly caused due to problems of retention and stability of the mandibular dentures. Masticatory function in these subjects is quite poor as compared with that of healthy dentate subjects. Complete denture patients require seven times more chewing strokes as compared with a person with a complete natural dentition to chew the food to half of the original particle size. Oral function improves significantly after supporting overdenture prostheses with implants. ${ }^{2}$

Treatment with conventional complete dentures poses a problem of poor retention because of the resorption of the bone. As the bone resorption is greater in the mandible as compared with maxilla, the mandibular denture is relatively more affected. ${ }^{3}$ Implant-supported overdentures are the treatment of choice for patients with resorbed alveolar ridges to obtain better retention. The overdenture is
DOI https://doi.org/

10.1055/s-0040-1709093

ISSN 2321-1482.
License terms

(ㅇ) (1) $\ominus \circledast$ 
an alternative to fixed implant-supported prosthesis for its relatively low-cost and in clinical cases where it is impossible to place multiple implants with appropriate number and arrangement in the arch to support a fixed prosthesis. ${ }^{4}$ Removable implant-retained dentures provide an alternative treatment that successfully replaces the esthetics and function along with minimal maintenance. ${ }^{1}$ A key factor in the success or failure of a dental implant is the manner in which stresses are transferred to the surrounding bone. These stresses transferred to the bone depend on loading type, bone implant interface, shape of the implant, and surface characteristics of implants. Stress induced in dental structures has been studied by different investigative methods like photoelastic study, finite-element analysis, and strain measurement on the surface of the bone. However, all these methods have certain limitations such as difficulties in modifications after modeling. The aim of this study was to evaluate the exerted stresses on implants and implant-abutment interface by comparing different attachment systems used for implant supported maxillary and mandibular overdentures using finite-element analysis.

\section{Materials and Methods}

The present study was conducted in the Department of Prosthodontics and Crown \& Bridge, Bhojia Dental College and Hospital, Baddi, Himachal Pradesh using the finite-element method (FEM), with the technical assistance from a mechanical engineer at CADD Centre, Sector 34, Chandigarh.

The following materials/equipments were used: Computer Intel core i9 processor, 64 GB RAM, 225 GB hard disk.

The softwares used were: Rapidform, Rapidform, Inc., United States, Solid Works software (Dassault System SolidWorks Corporation, Waltham, United States), ANSYS software V. 18.1 (ANSYS, Inc., United States).

\section{Methodology}

The geometric models of maxilla and mandible were created from the CT images obtained by the CT scan of the maxilla and mandible. The information was then transferred to the RapidForm software, where the CT scan images were assembled to create different views. Then, the data was imported into SolidWorks software to create three-dimensional (3D) models of mandible and maxilla along with implants, attachments and denture. Models with different attachments and implants in maxilla and mandible were modeled. The models were then transferred to the ANSYS software. Thereafter, meshing was performed, that is, the process of converting the geometric model into the finite element model. The finite element model consisted of nodes and elements. The material properties of implant, bone, and attachments were then entered in the preprocessing stage. Then, applied force and boundary conditions were applied in the solution stage.
Models were then solved in the solving stage. The analysis was conducted and results were collected in the postprocessing stage.

\section{Model Generation and Description}

The first step in modeling the overdenture was to prepare an editable geometry in the computer. A 3D geometry of maxilla and mandible was generated using computed tomography (CT). In this process, models of mandible and maxilla were prepared using CT scan technology. The mandible and skull were scanned and CT images were prepared. The information was then transferred to the RapidForm software, where the CT scan photos were assembled to create different views for the models. Then, the data was imported into the SolidWorks software to create 3D models of mandible and maxilla. The teeth were removed to complete the models of edentulous maxilla and mandible. The model was then modified to incorporate the cortical and cancellous bones. A uniform thickness of mucosa of $2 \mathrm{~mm}$ was modeled on the maxilla and mandible. Thereafter, models with different attachments, that is, bar/clip and ball/O-ring for mandible and maxilla were modeled, over which overdenture was modeled.

\section{Mandible}

Three models were generated for the mandible. In the first model, there were two free-standing implants in the interforaminal region with ball attachment supporting an overdenture. In the second model, there were two implants placed in the interforaminal region. The implants were connected with a bar. The attachment used was a bar and clip, which supported the overdenture. In the third model, there were four implants connected by a bar which supported the overdenture ( - Fig. 1 ).

\section{Maxilla}

Two models were generated for maxillary overdentures. In the first model, there were four implants connected with a bar. In the second model, there were four free-standing implants with ball and O-ring attachment ( - Fig. 2).

\section{Material Properties}

All materials used in the models were considered to be isotropic, homogeneous, and linearly elastic. The elastic properties of bone model were obtained from the literature. Material properties were incorporated in the respective models. Modulus of elasticity and Poisson's ratio of bone, implants, denture, mucosa, and different attachments were incorporated in the models (-Table $\mathbf{1}$ ). The bar was made up of $\mathrm{Co}-\mathrm{Cr}$ alloy. Ball abutment was made up of stainless steel. As there were a large number of mating parts in each model, contact areas were defined and simulated properly in the finite-element model. These surfaces were defined in accordance with their physical use and contact conditions. In the ball attachment, contacts were imposed between the ball abutment and the housing. For 


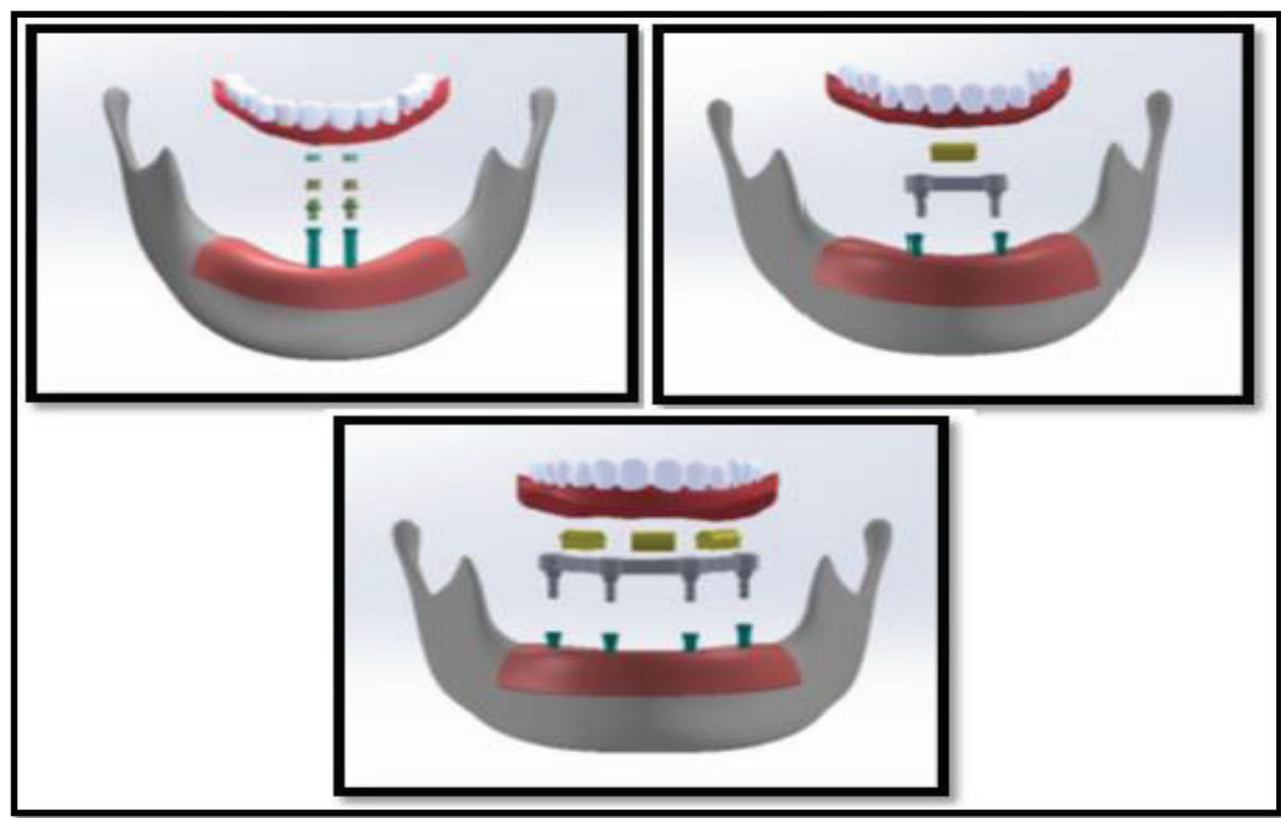

Fig. 1 Mandibular models.

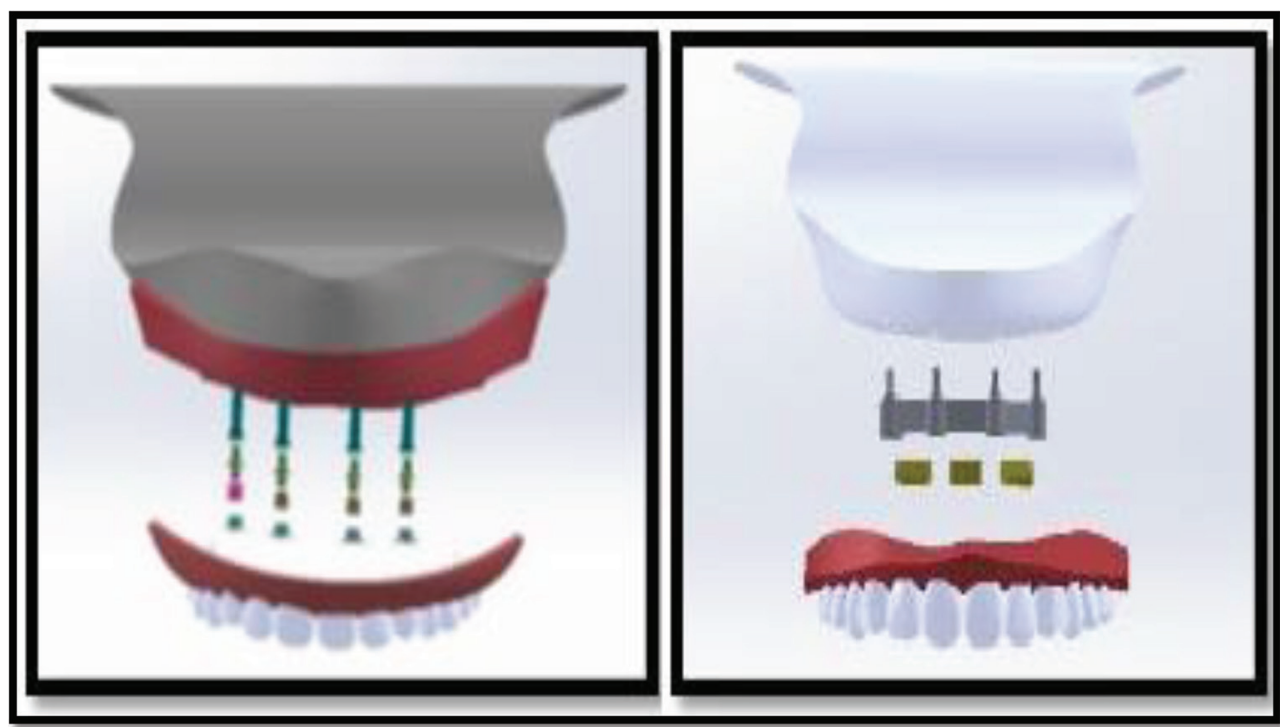

Fig. 2 Maxillary models.

the bar-clip attachment, contact was imposed between the bar and clip. In addition, due to a perfect bond between the implants and the bones, they were assumed totally osseointegrated.

\section{Finite-Element Model}

Finite-element analysis of the models were performed using ANSYS Workbench software V18. Meshing was performed ( - Fig. 3): the finer the mesh more accurate are the results. Hexagonal meshing was done. In this study, nodes and elements are formed after meshing. In any finite-element analysis, the accuracy of the results is based on the number of proper elements and the type of well-defined contacts between sliding surfaces in the model. In this analysis, finite-element models were solved using several mesh generations. In each model, the highest von-Mises stress in each component was chosen as stress value.

\section{Loading}

The models were loaded in the canine region and in the first molar region bilaterally. Axial force of $35 \mathrm{~N}$ was applied, horizontal force of $10 \mathrm{~N}$ (lingual), and oblique force of $70 \mathrm{~N}$ (buccal) was applied. The forces of different magnitudes were applied separately in the canine and the first molar region. Each model in maxilla as well as mandible was subjected to three different forces in the canine region as well as the first molar region (-Figs. $\mathbf{4}$ and $\mathbf{5}$ ). The red area shows the highest amount of stresses. 


\section{Results}

\section{Comparison in Stress Distribution in Implants between Different Attachments}

In the mandible, when forces were applied in the canine region, maximum stress on implants was seen in the model-1, that is, two implants with ball attachments, followed by model- 2 with two implants connected by a bar. The least amount of stress was seen in the model- 3 with four implants connected by a bar. When forces were applied in the molar region, maximum stress on implants was seen in model-1 with ball attachments, followed by model-2 with two implants connected by bar. The least amount of stress was seen in the model- 3 with four implants connected by a bar (-Tables $\mathbf{2}$ and $\mathbf{3}$ ) (-Figs. $\mathbf{6}$ and $\mathbf{7}$ ).

In the maxilla, when forces were applied in the canine region, maximum stress on implants was seen in model-4, where there were four implants with ball attachment. The least amount of stress was seen in the model- 5 with four

Table 1 Material properties

\begin{tabular}{|l|l|l|}
\hline Material & $\begin{array}{l}\text { Young's modulus } \\
\text { (MPa) }\end{array}$ & Poisson's ratio \\
\hline Cortical bone & 13700 & 0.30 \\
\hline Trabecular bone & 1370 & 0.30 \\
\hline Mucosa & 2.8 & 0.40 \\
\hline Implant & 110,000 & 0.35 \\
\hline Overdenture & 2000 & 0.35 \\
\hline Bar (Co-Cr alloy) & 218000 & 0.31 \\
\hline Clip & 3000 & 0.28 \\
\hline Ball (stainless steel) & 19000 & 0.31 \\
\hline O-ring & 5 & 0.45 \\
\hline
\end{tabular}

implants connected by a bar. When forces were applied in the molar region, maximum stress on implants was seen in model-4 which had four implants with ball attachment. The least amount of stress was seen in model-5 with four implants connected by a bar ( - Table 4 ).

\section{Comparison in Stress Distribution on the Body of Implant}

In all the models, in maxilla as well as mandible, maximum stress was seen around the neck of the implants and on its upper threads. The stress decreased gradually toward the apex of the implant (-Tables 2-5).

\section{Comparison in Stress Distribution in Implant When Forces were Applied in the Canine and First Molar Region}

In all the mandible models, the stress seen on the implants when axial force was applied in the canine region was greater in comparison to the force applied in the first molar region. The stress seen on the implants was greater when oblique forces were applied in the molar region (-Tables 2 and 3). In the maxilla, stress seen on implants was greater when forces were applied in the molar region ( - Tables 4 and $\mathbf{5}$ ).

\section{Comparison in Stress Distribution at the Attachment-Implant Interface}

In the mandible, the highest amount of stress at the interface was seen with the ball attachment, and the least amount of stress was seen in the bar attachment connecting four implants (-Tables 2 and $\mathbf{3}$ ).

In the maxilla, the highest amount of stress at the interface was seen with the ball attachment and the least amount

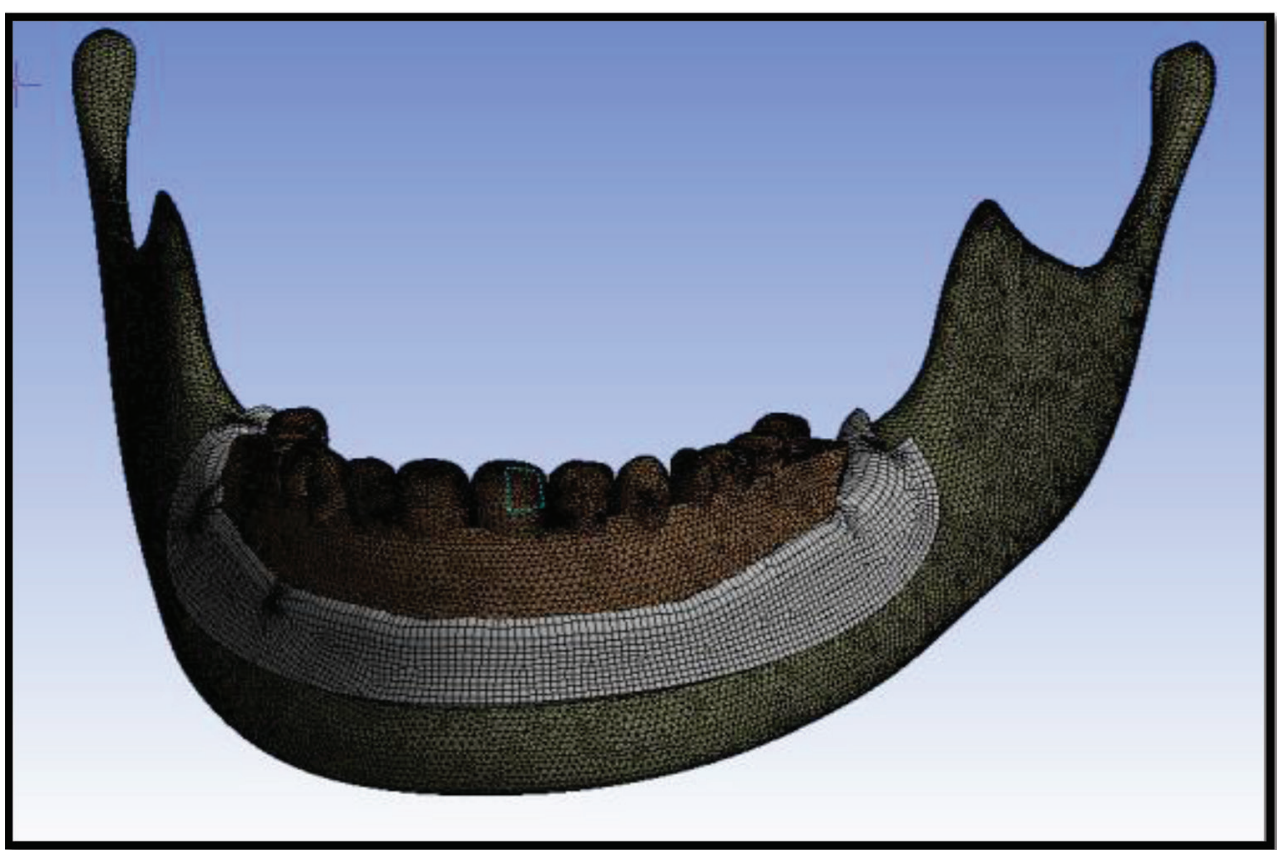

Fig. 3 Meshing. 


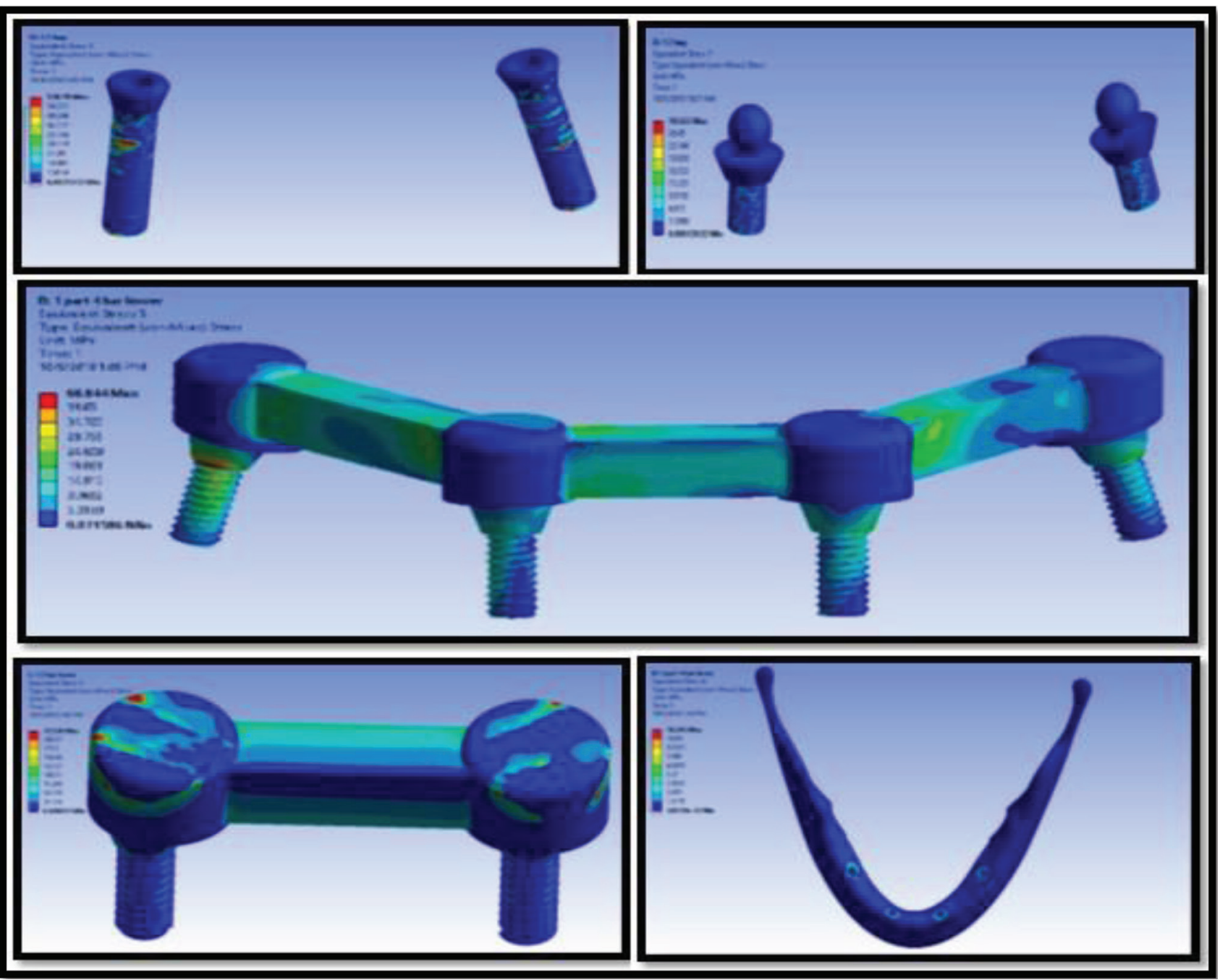

Fig. 4 Stresses in mandibular models.

of stress was seen with the bar attachment connecting four implants ( $\mathbf{- T a b l e s} \mathbf{4}$ and $\mathbf{5}$ ).

\section{Comparison in Stress Distribution seen at the Crestal Bone}

In the mandible, the highest stress on crestal bone was seen in the model with ball attachments. Least stress was seen in the model with four implants connected by a bar ( - Tables 2 and $\mathbf{3}$ )

(-Figs. 8 and 9 ).

In the maxilla, the highest stress on crestal bone was seen in the model with ball attachments. Least stress was seen in the model with four implants connected by a bar (-Tables 4 and 5).

\section{Discussion}

Different attachments available today may be used to retain implant-retained overdentures. However, the selected attachment used in implant-retained overdentures has an effect on implant survival rate, marginal bone loss, soft tissue complications, retention, stress distribution, maintenance complications, and patient's satisfaction. The maximum stress on implant was seen at its neck and at its upper threads and on the crestal bone. The stresses were distributed better when implants were splinted with a bar. The stresses seen on the implant and the surrounding bone was lesser in comparison to the ball attachment. As per our study, we compared overdenture attachments in maxilla and mandible with bar attachments and ball attachments and two implants versus four implants' overdenture. In this study, forces were applied axially $(35 \mathrm{~N})$, obliquely $(70 \mathrm{~N})$, and horizontally (10N) at the canine area and first molar area; stresses were evaluated at three levels: attachment level, implant-attachment interface, and implant level. On the implant body, the stresses were evaluated at the cervical, middle, and apical levels. The results were compared to conclude the best possible combination of implant number and type of attachment to be used for a successful overdenture in maxilla and mandible. The maximum stress on implant was seen at its neck and at its upper threads as well as on the crestal bone. Menicucci et al $(1998)^{5}$ in their study also observed that maximum stresses were concentrated around the neck of the implant and its upper threads. 

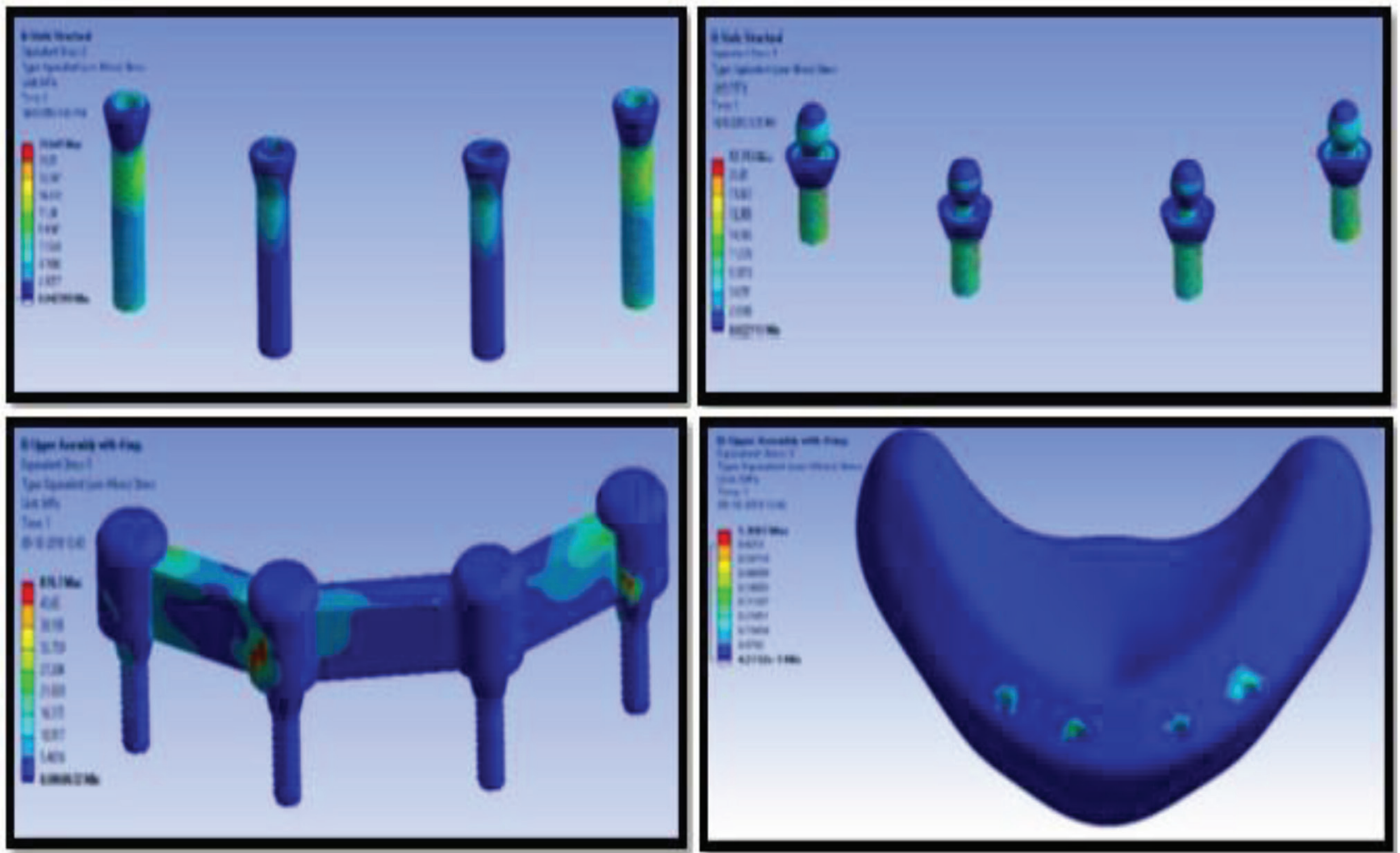

Fig. 5 Stresses in maxillary models.

Table 2 Stresses in mandible having two implants with bar attachment when forces were applied in the molar region

\begin{tabular}{|l|l|l|l|l|}
\hline \multicolumn{2}{|c|}{} & Axial (35N) & Oblique (70N) & Horizontal (10N) \\
\hline \multirow{3}{*}{ Implant level-right side } & Cervical & 9.66 & 18.85 & 1.90 \\
\cline { 2 - 5 } & Middle & 11.59 & 17.57 & 1.70 \\
\cline { 2 - 5 } & Apical & 1.97 & 6.28 & 0 \\
\hline \multirow{2}{*}{ Implant level-left side } & Cervical & 11.59 & 18.85 & 1.37 \\
\cline { 2 - 5 } & Middle & 9.66 & 17.57 & 0 \\
\cline { 2 - 5 } & Apical & 3.86 & 6.28 & 2.74 \\
\hline Attachment & 17.56 & 26.34 & 0.28 \\
\hline Implant attachment interface right side & 6.41 & 4.48 & 0.28 \\
\hline Implant attachment interface left side & 7.69 & 4.48 & 0.20 \\
\hline Crestal bone right side & 1.28 & 1.92 & 0.20 \\
\hline Crestal bone left side & 1.28 & 1.92 & \\
\hline
\end{tabular}

Similar results were obtained by Daas et al (2008). ${ }^{6}$ John et al $(2012)^{3}$ also observed that the greatest stress concentrations were seen at the crest of the cortical bone irrespective of the loading conditions.

The stresses were distributed better when implants were splinted with a bar. The stresses seen on the implant and the surrounding bone were lesser in comparison to the ball attachment. Similar results were obtained by Bilhan et al (2014). ${ }^{7}$ They said that the increase in number of implants and use of a splinted attachment could be preferred to reduce forces around the implants. He observed lower stress values with the bar attachment. Satpathy et al $(2015)^{8}$ observed similar results. He observed that the forces were distributed better with the bar/clip attachment system in comparison to the ball/O-ring attachment system.

In contrast to these results, Tokuhisa et al $(2003)^{9}$ concluded in their study that the use of the ball/O-ring attachment distributed the stress better than the two implants splinted by a bar. El-Anwar and Mohammed (2014) ${ }^{1}$ also observed similar results. They reported 1 percent increase in stress in case of two implants connected by a bar.

\section{Summary and Conclusion}

In this study, stress distribution in five different models with different attachments were evaluated using finite-element 
28 Finite Element Analysis on Implant Supported Overdentures Javaid et al.

Table 3 Stresses in mandible having two implants with ball attachments when forces were applied in the molar region

\begin{tabular}{|l|l|l|l|l|}
\hline \multicolumn{2}{|c|}{} & Axial (35N) & Oblique (70N) & Horizontal (10N) \\
\hline \multirow{3}{*}{ Implant level-right side } & Cervical & 11.59 & 31.41 & 2.05 \\
\cline { 2 - 5 } & Middle & 12.56 & 18.85 & 2.05 \\
\cline { 2 - 5 } & Apical & 9.66 & 12.56 & 2.00 \\
\hline \multirow{2}{*}{ Implant level-left side } & Cervical & 12.56 & 31.41 & 2.09 \\
\cline { 2 - 5 } & Middle & 10.62 & 17.57 & 2.05 \\
\cline { 2 - 5 } & Apical & 3.86 & 13.18 & 2.00 \\
\hline Attachment right side & 26.34 & 35.14 & 2.71 \\
\hline Attachment left side & 26.34 & 35.14 & 2.71 \\
\hline Implant attachment interface-right side & 7.69 & 5.28 & 0.42 \\
\hline Implant attachment interface-left side & 8.33 & 3.84 & 0.56 \\
\hline Crestal bone right side & 1.28 & 1.77 & 0.40 \\
\hline Crestal bone left side & 1.92 & 2.12 & 0.30 \\
\hline
\end{tabular}

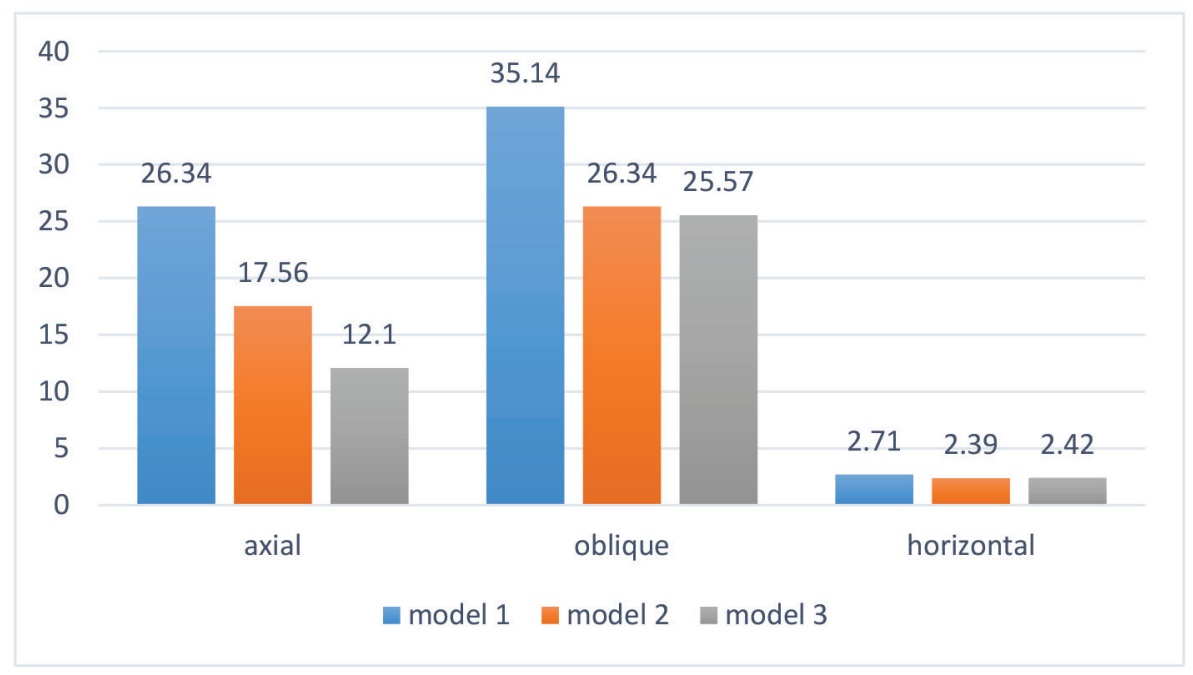

Fig. 6 Stresses seen on attachments under all loading conditions when forces were applied in the mandible.

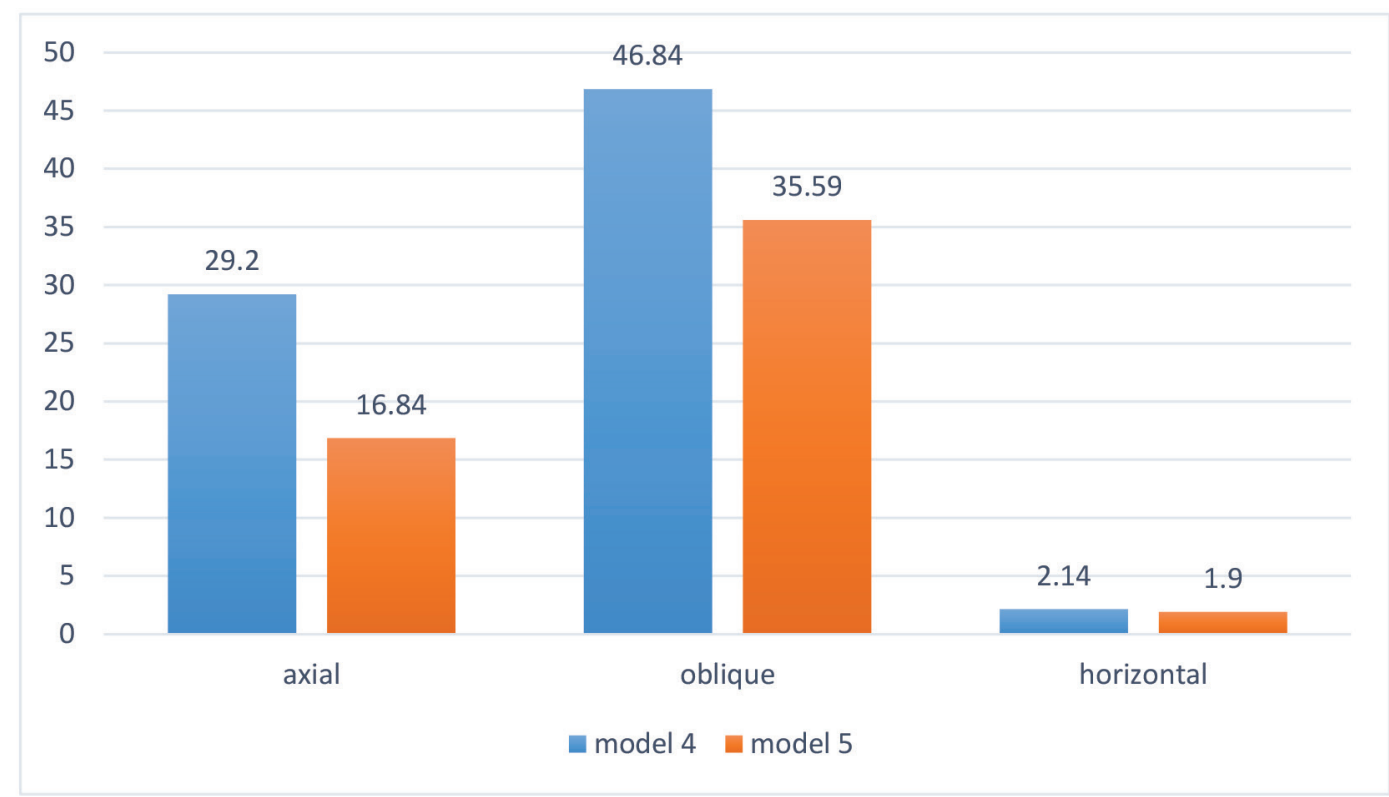

Fig. 7 Stresses seen on attachments under all loading conditions in the maxilla. 
Table 4 Stresses in maxilla having four implants with bar attachments when forces were applied in the molar region

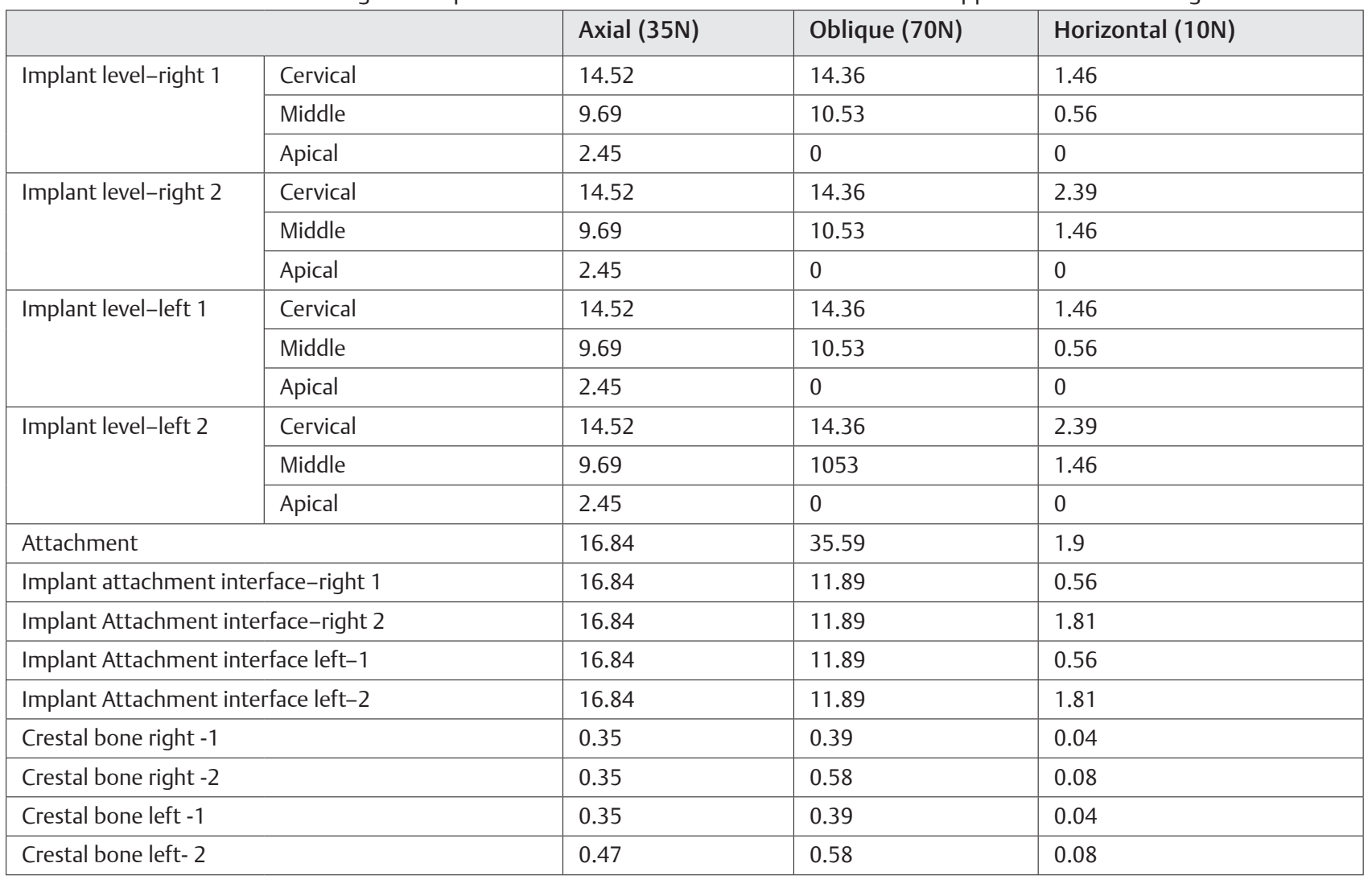

Table 5 Stresses in maxillary model having four implants with ball attachments when forces were applied in the molar region

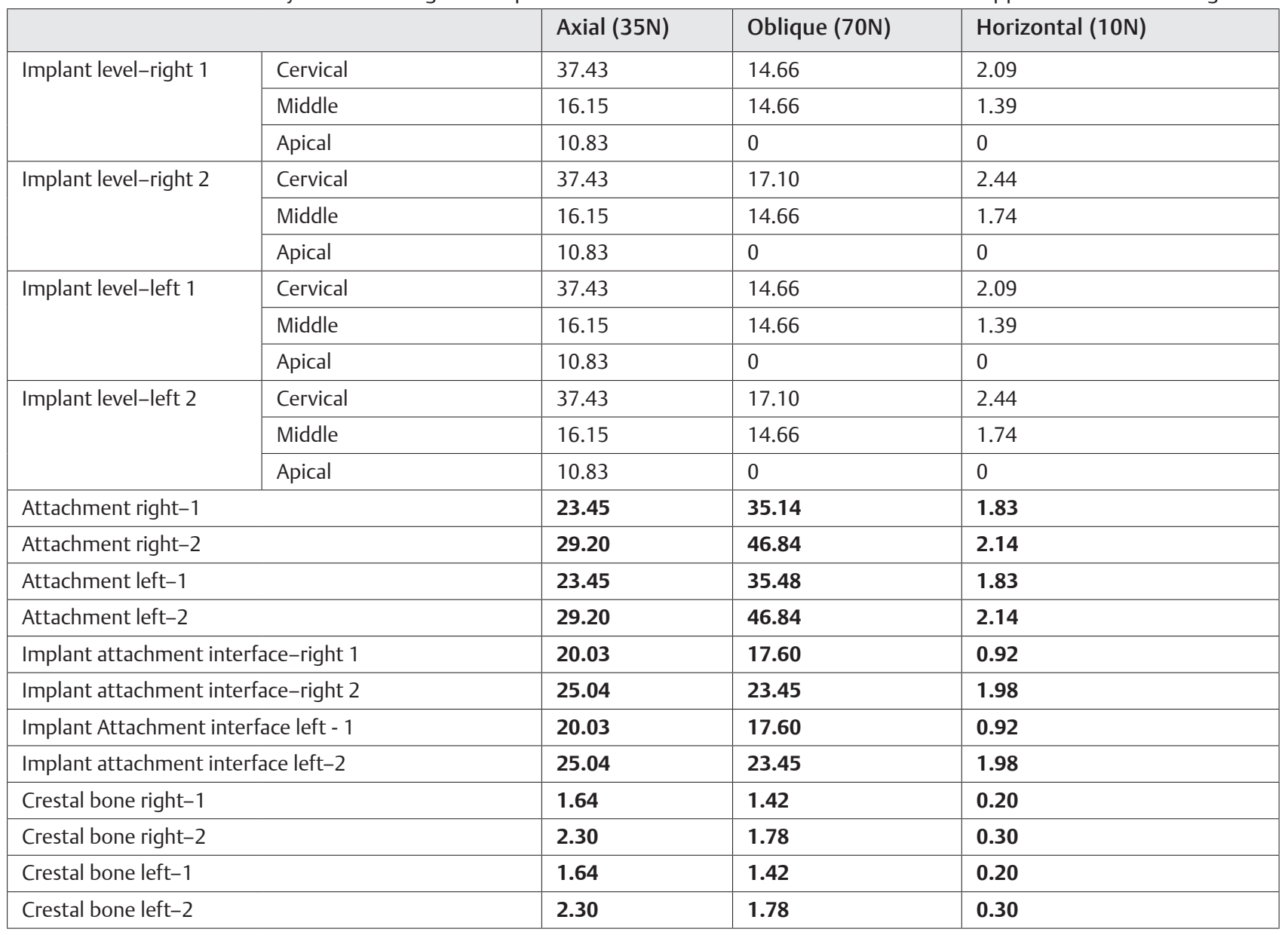




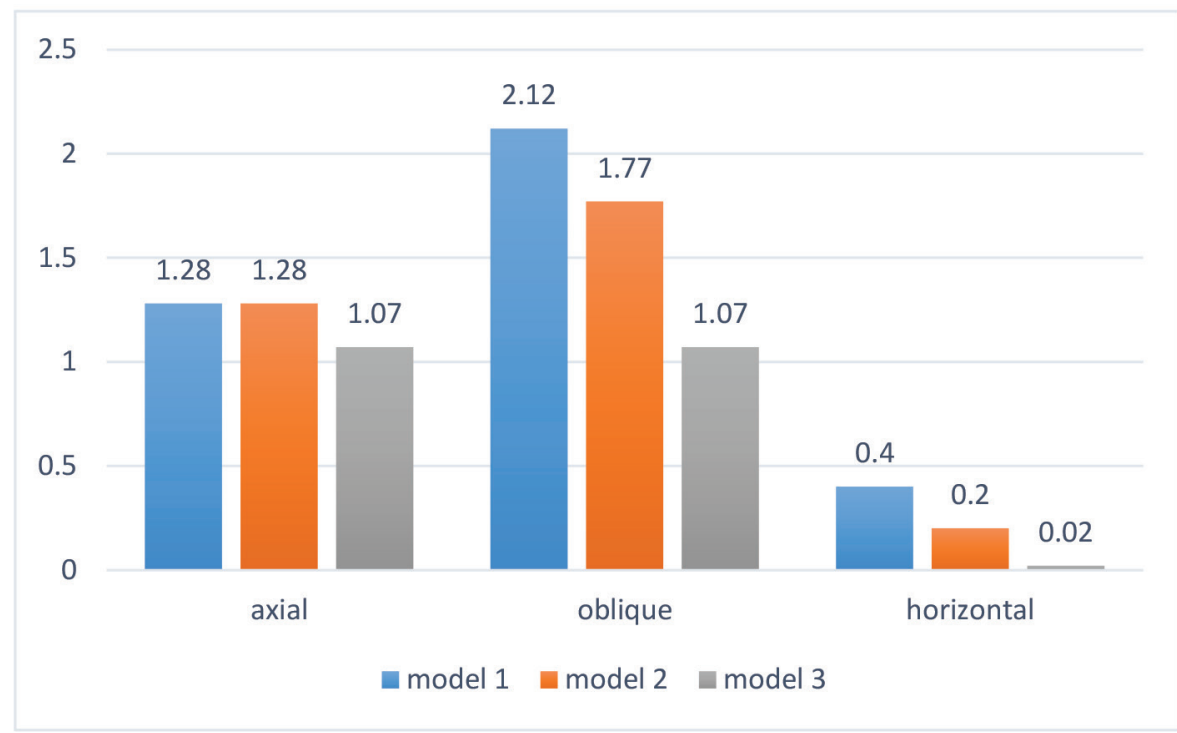

Fig. 8 Stresses on crestal bone under all loading conditions in the mandibular molar region.

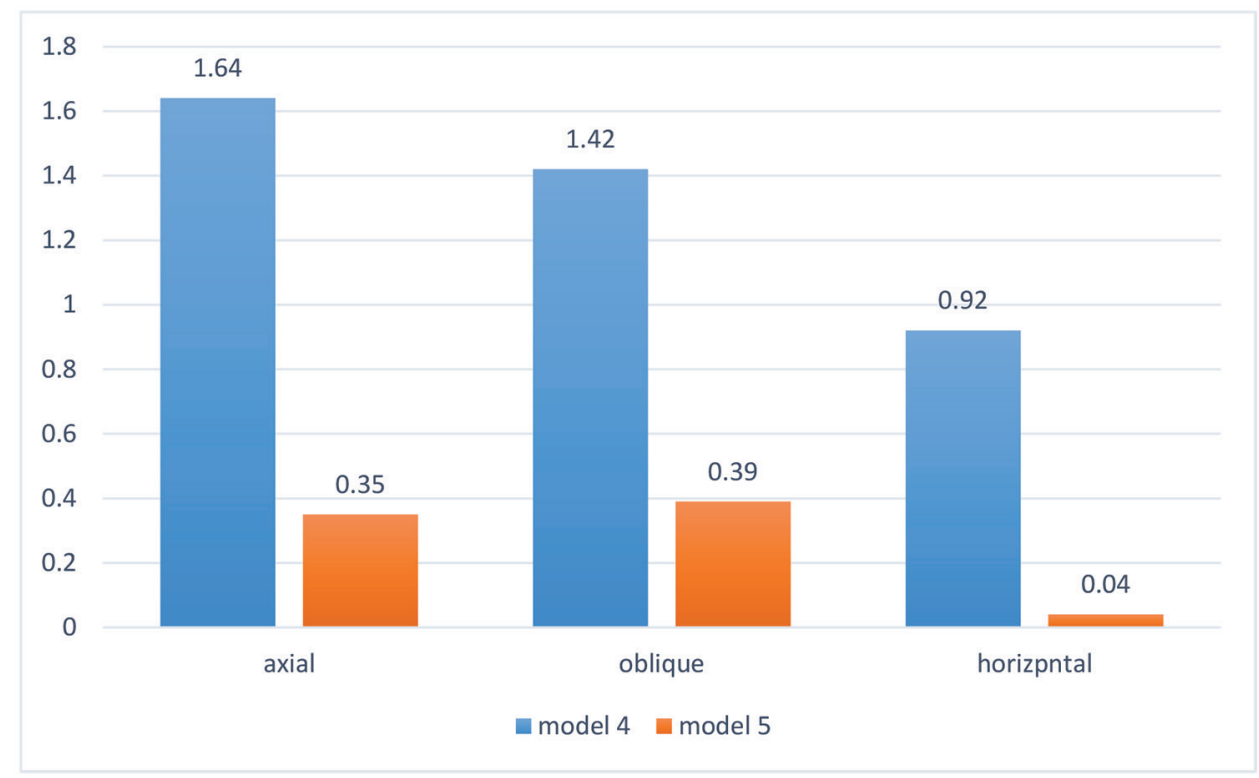

Fig. 9 Stresses seen on crestal bone under all loading conditions in maxillary molar region

analysis. The studied attachment systems were ball/0-ring and bar-clip attachments. In the mandible, three models were generated, two implants with ball attachments, two implants with bar, and four implants connected with a bar. In the maxilla, two models were generated, four implants with ball attachments and four implants connected with bar. Forces were applied bilaterally on each model in the canine and molar region separately. The forces applied were $35 \mathrm{~N}$ axially, $70 \mathrm{~N}$ obliquely, and $10 \mathrm{~N}$ horizontally. The ball attachments models showed the highest amount of stresses on the bone and on the implants under different loading conditions in the maxilla and mandible. The bar-clip attachment with four implants showed least stress in the maxilla as well as in the mandible. The bar on four implants had better stress distribution in comparison with the bar on the two implants.
The most stressed points in the bone were located around the neck of the implant and at its upper threads.

In all models, the highest values of von-Mises stresses in the cortical and cancellous bones were lower than their respective ultimate strength values. So, bone resorption does not occur. Since the bar attachment with four implants transferred least amount of stress to the bone and to the implant, it is advisable to use a bar attachment with four implants whenever possible in the clinical situations. Stresses seen with the ball attachments are slightly greater when compared with two implants connected with a bar and are well within the ultimate strength values. So, the ball attachments can also be used successfully. In the maxillary arch, as the bone is trabecular and cortical bone is thin or sometimes absent, the use of at least four implants splinted by bar is recommended. 


\section{Funding}

None.

\section{Conflict of Interest}

None declared.

\section{References}

1 El-Anwar MI, Mohammed MS. Comparison between two low profile attachments for implant mandibular overdentures. J Genet Eng Biotechnol. 2014;12(1):45-53

2 van Kampen FMC, van der Bilt A, Cune MS, Fontijn-Tekamp FA, Bosman F. Masticatory function with implant-supported overdentures. J Dent Res 2004;83(9):708-711

3 John J, Rangarajan V, Savadi RC, Satheesh Kumar KS, Satheesh Kumar P. A finite element analysis of stress distribution in the bone, around the implant supporting a mandibular overdenture with ball/o ring and magnetic attachment. J Indian Prosthodont Soc 2012;12(1):37-44

4 Mariano LO, Sartori EA, Broilo JR, Shinkai RS, Corso L, Marczak RJ. Stresses in implant-supported overdentures with bone resorption: a 3-D finite element analysis. Rev Odonto Ciênc 2012; 27(1):41-46
5 Menicucci G, Lorenzetti M, Pera P, Preti G. Mandibular implant-retained overdenture: finite element analysis of two anchorage systems. Int J Oral Maxillofac Implants 1998;13(3):369-376

6 Daas M, Dubois G, Bonnet AS, Lipinski P, Rignon-Bret C. A complete finite element model of a mandibular implant-retained overdenture with two implants: comparison between rigid and resilient attachment configurations. Med Eng Phys 2008; 30(2):218-225

7 Arat Bilhan S, Baykasoglu C, Bilhan H, Kutay O, Mugan A. Effect of attachment types and number of implants supporting mandibular overdentures on stress distribution: a computed tomography-based 3D finite element analysis. J Biomech 2015; 48(1):130-137

8 Satpathy S, Babu CL, Shetty S, Raj B. Stress distribution patterns of implant supported overdentures-analog versus finite element analysis: a comparative in-vitro study. J Indian Prosthodont Soc 2015;15(3):250-256

9 Tokuhisa M, Matsushita Y, Koyano K. In vitro study of a mandibular implant overdenture retained with ball, magnet, or bar attachments: comparison of load transfer and denture stability. Int J Prosthodont 2003;16(2):128-134 